\title{
Comparison of the qCON and qNOX indexes for the assessment of unconsciousness level and noxious stimulation response during surgery.
}

Umberto Melia $^{1}$, Eva Gabarron ${ }^{1}$, Mercé Agusti ${ }^{2}$, Nuria Souto ${ }^{2}$, Patricia Pineda ${ }^{1}$, Joan Fontanet ${ }^{1}$, Montserrat Vallverdu ${ }^{3}$, Erik Weber Jensen ${ }^{1,2,3}$, Pedro Gambus ${ }^{2,4,5}$

${ }^{1}$ R\&D Department, Quantium Medical, Barcelona, Spain.

${ }^{2}$ Systems Pharmacology Effect Control \& Modeling (SPEC-M) Research Group, Anesthesiology Department, Hospital CLINIC de Barcelona, Barcelona, Spain

${ }^{3}$ Centre for Biomedical Research (CREB), Automatic control and Informatic (ESAII) Department, UPC-Barcelonatech, Barcelona, Spain.

${ }^{4}$ Neuroimmunology Research Program Institut de Investigacions Biomèdiques August Pi Sunyer (IDIBAPS), Barcelona, Spain.

${ }^{5}$ Department of Anesthesia and Perioperative Medicine, University of California San Francisco, San Francisco, California, United States of Americanesthesiology.

Corresponding author: Umberto Melia

e.mail: $\underline{u m g @ \text { quantiummedical.com }}$

phone-number: +34937021950

\begin{abstract}
Purpose. The objective of this work is to compare the behavior of two electroencephalogram (EEG) based indices after drug induction and during recovery of consciousness.

Methods. Data was recorded from 140 patients scheduled for general anaesthesia with a combination of propofol and remifentanil. The qCON 2000 monitor (Quantium Medical, Barcelona, Spain) was used to calculate the qCON and qNOX. The fall times and the rise times were defined at the start and at the end of the surgery. Loss of response to verbal command and loss of eye-lash reflex were assessed during the transition from awake to anesthetized, defining the state of loss of consciousness (LOC). Movement as a response to laryngeal mask (LMA) insertion was interpreted as the response to the nociceptive stimuli. The patients were classified as movers or non-movers. The values of qCON and qNOX were statistically compared.
\end{abstract}

Results. The qCON reached 65 in median (25th; 75th percentile) at $198.0(114.0 ; 245.0) \mathrm{s}$ after anaesthesia induction, while the qNOX fall time was significantly longer ( $p$-value $<0.05$ ): 249.0 $(189.0 ; 322.0) \mathrm{s}$. At the end of the surgery, the qNOX started to increase to 85 at $5.0(-44.0$; 46.0) s after recovery, while the qCON at $88.0(-151.0 ; 40.0) \mathrm{s}(\mathrm{p}$-value $<0.05)$. The results show that the qCON has a predictive value of loss of consciousness such as loss of verbal command and eyelash reflex while the qNOX has a predictive value of response to noxious stimulation such as LMA insertion.

Conclusion. The indices qCON and qNOX were able to detect differences between the times of actions of hypnotic and analgesic agents. The qCON showed faster decrease during induction while the qNOX showed a faster increase during recovery.

Keywords: Anesthesia monitor, nociception, electroencephalography, clinical indexes. 


\section{Introduction.}

It remains a challenge whether the antinociception/nociception balance can be assessed as an individual component of depth of anaesthesia. The hypnotic effect can be assessed by indices derived from the EEG, a number of different methods are available as experimental or commercial devices [1-6] whereas the assessment of nociception is less accepted due to the complexity and interpretation of the measurement.

Several methods have been proposed to assess and quantitate the nociceptive response during general anesthesia [8-11]

Autonomic nervous system measures, for example Heart Rate Variability (HRV) [12] or Skin Conductance (SC) [13] and parameters extracted, have been proposed and used by several authors. HRV and SC are correlated with sympathetic activity and therefore, monitors based on these parameters can measure the increase in sympathetic activity. However, increases in sympathetic activity can be caused by other factors not related to pain. Combinations of previous methods have also been described as potential indicators of nociceptive response as described by Schneider [14] or Ben-Israel [15]. Changes in pupil size [16, 17] or other HRV derived parameters studying parasympathetic activity [18] in response to opioid concentrations or noxious stimulation have also been proposed as methods to assess the level of analgesia in surgical patients.

Predicted concentrations of drugs have also been used to define probability of response to a given stimulus as a function of the intensity of stimuli and the synergistic relation between propofol and opioids. The best studied is the Noxious Stimulation Response Index (NSRI)[19] which is an estimate of the interaction between predicted effect site concentrations (Ce) of propofol and remifentanil. The NSRI is based on the hierarchical interaction model defined by Bouillon et al. in 2004[20]. The NSRI can be expressed as the probability to tolerate a certain reference stimulus for example tolerance of laryngoscopy. Recently, a new model of the NSRI has been developed to include the endtidal concentration of Sevoflurane as well [21]. The NSRI was also validated by von Dincklage [22], showing that the NSRI could predict movement (but not heart rate) responses to incision satisfactorily.

The analysis of brain signals such as spontaneous EEG activity or the Auditory Evoked Potentials (AEP) have also been used. The main advantage is that they reflect the cortical response to anesthetic drug effects and noxious stimulation. The methods based on EEG analysis are typically empirical in their origin as there is no clear consensus of which frequency bands or features of the EEG correlate best to the antinociception/nociception balance during analgesia.

Previous work from our group showed that the qNOX, a parameter extracted from the raw EEG using an adaptive neuro-fuzzy inference system (ANFIS), could predict the likelihood of movement response to different anesthetic and surgical stimuli [23]. ANFIS is a data driven modelling approach based on the principles of Fuzzy Logic.

The objectives of the present study are to estimate the values of qCON, a biomarker of hypnotic effect under general anesthesia, and qNOX below which the loss of consciousness and loss of response to noxious stimulation are achieved and then to test the hypothesis that loss of consciousness occurs before loss of nociception by analyzing the fall and rise times for qCON 
and qNOX at the beginning and at the end of the surgery. This can also contribute to deeper analyse the behaviour of the qCON and the qNOX as indexes of consciousness level and probability of response to noxious stimulation, during general anesthesia for surgical procedures as well as the response of both indexes in relation to changes of propofol and remifentanil effect site concentrations.

\section{Methods}

After IRB approval (Committee on Ethics in Research, Hospital CLINIC de Barcelona $\mathrm{n}^{\circ}$ 2013/8356) and written informed consent, data was recorded from 140 subjects. Patients were scheduled to receive general anaesthesia with a combination of propofol and remifentanil for different surgical procedures in the Ambulatory Surgery facility at Hospital CLINIC de Barcelona.

\section{General Anesthesia}

The TCI system (Base Primea, FreseniusKabi AG, Bad Homburg, Germany) administered propofol and remifentanil according to the predictions of pharmacokinetic and pharmacodynamic models. In both cases the TCI was targeting the effect-site applying the Schnider model for propofol (Ce prop) [24,25] and the Minto model for remifentanil (Ce remi) [26,27]. Surgical procedures were ambulatory interventions including inguinal hernia repair, laparoscopic cholecystectomy, gynecologic laparoscopy and other gynecologic procedures. There were no specific requirements for anesthetic management with regards to preventing movement. Movements after stimuli were registered.

The qCON and qNOX indices were continuously recorded. The data from the qCON and the qNOX indices were stored in a PC by means of proprietary software, qCON display (Quantium Medical, Spain). The qCON, qNOX, EMG, Burst Suppression and SQI (Signal Quality Index) were stored in a text file. Data with a $\mathrm{SQI}<50$ were rejected. The data from the TCI system (Ce prop and Ce remi) were recorded with Rugloop (Demed, Belgium).

\section{Clinical end points.}

Loss of response to verbal command and loss of eye-lash reflex were assessed during the transition from awake to anesthetized, defining the state of loss of consciousness (LOC). The baseline values for the indices were the mean of the 1 min interval immediately before the TCI system was started while the anesthetized value was the mean taken over the 1 min interval immediately after LOC. Movement as a response to laryngeal mask (LMA) insertion was recorded. Movement in the period of one minute after applying the stimuli was interpreted as the response to the nociceptive stimuli. All relevant clinical endpoints were entered online as an event in Rugloop. The patients were classified as movers or non-movers and the mean value for the qCON and qNOX were calculated over the 1 min period after the stimulus.

Speed of loss of consciousness and loss of response to noxious stimuli.

In order to analyze the responses of the qCON and qNOX to the changes of hypnotic and analgesic concentrations and hence to assess the speed of loss of consciousness and loss of response to noxious stimuli, the fall and rise times of the two indices were defined at the beginning and at the end of the surgery. The fall times (Figure 4a) were defined as the 
difference between the times when the effect site concentration of propofol or remifentanil was above zero $\left(T_{0}\right)$ and the time when qCON and qNOX reached a value below $x\left(T_{<x}\right)($ Eq. 1-2).

$$
\begin{aligned}
& \text { Fall time qCON }=T_{<x}-T_{0} \\
& \text { Fall time qNOX }=T_{<x}-T_{0}
\end{aligned}
$$

where $T<_{<x}=\min \left\{t \mid \mathrm{qCON}(t)<x \vee \operatorname{qNOX}(t)<x \quad\right.$ and $T_{0}=\min \{t \mid \operatorname{Ce} \operatorname{prop}(t)>0 \vee \mathrm{Ce}$ remi $(t)>0\}$, where $t$ includes the time instants of the recorded qCON and qNOX of each patient.

The rise times (Figure 4b) were defined as the difference between the time of recovery of consciousness (eye opening to verbal command) or response to noxious stimuli $\left(T_{R C}\right)$ and the times when qCON and qNOX reached a value above $x\left(T_{>x}\right)($ Eq. 3-4).

$$
\begin{aligned}
& \text { Rise time } \mathrm{qCON}=T_{R C}-T_{>x} \\
& \text { Rise time } \mathrm{qNOX}=T_{R C}-T_{>x}
\end{aligned}
$$

where $\mathrm{T}_{>_{\mathrm{X}}}=\min \left\{t \mid t>T_{<x} \wedge(\forall t \rightarrow \mathrm{qCON}(t)>x \vee \mathrm{qNOX}(t)>x)\right\}$ and $T_{R C}=\min \{t \mid t>T$ $<_{x} \vee t=$ time when patients open eye or response to a noxious stimuli $\}$

\section{Statistics.}

A power calculation was performed aiming at a power of 0.9 and a level of significance of 0.05 . Previous experience showed that the SD of the qNOX is less than 20, and we considered a change of 10 units in response to noxious stimulation as significant, hence the standardized difference was $10 / 20=0.5$. According to Altman [28] with these conditions the necessary sample size is 140 .

The prediction probability, $\mathrm{Pk}$ [29], was used to assess the ability of the qCON and qNOX to predict the loss of consciousness and the responses to noxious stimulation. The $\mathrm{Pk}$ and its standard error (SE) were calculated using the jack-knife estimate which has the advantage that the variance can be estimated by the Student's t distribution. To test for significance a Kruskal Wallis test was applied. The test was considered significant if $\mathrm{p}$-value $<0.05$.

Significant differences of the rise and fall times were tested using Mann Whitney $U$ test and Wilcoxon signed-rank test. 


\section{Results}

A total of 140 patients were included and their data analyzed. There were 68 men and 72 women, age 55 (17-88) years old, weight 70 (42-102) Kg.

Figure 1 shows an example of time course of qCON and qNOX of a representative patient.

Tables 1, 2 and 3 show the results of responses to verbal command, loss of eye-lash reflex and response to LMA insertion. A Kruskal Wallis test was used to test for significance. There was a total of 165 noxious events where 146 were non responders and 19 were responders.

Based on these results we consider the range between $65<\mathrm{qCON}<85$ for loss of consciousness (during non-steady state conditions such as induction) and $65<\mathrm{qNOX}<85$ as loss of response to noxious stimulation (placement of LMA). Hence, the limits of these ranges are used as $x$ in equations $1-4$, as it is shown in figure 2 .

Table 1. Loss of response to verbal command

\begin{tabular}{|l|c|c|c|c|}
\hline & qCON & & qNOX & \\
\hline & Mean & SD & Mean & SD \\
\hline Response & 92.98 & 9.93 & 95.18 & 9.21 \\
\hline No response & 67.72 & 17.88 & 88.25 & 13.42 \\
\hline Pk(SE) & 0.91 & 0.03 & 0.67 & 0.06 \\
\hline P (Krus Wal) & 0.00 & & 0.01 & \\
\hline
\end{tabular}

Table 2. Loss of response to eyelash reflex

\begin{tabular}{|l|c|c|c|c|}
\hline & qCON & & qNOX & \\
\hline & Mean & SD & Mean & SD \\
\hline Response & 91.93 & 10.89 & 94.81 & 9.45 \\
\hline No response & 58.27 & 16.80 & 79.93 & 19.22 \\
\hline Pk(SE) & 0.94 & 0.02 & 0.81 & 0.05 \\
\hline P (Krus Wal) & 0.00 & & 0.00 & \\
\hline
\end{tabular}

Table 3. Response to LMA insertion

\begin{tabular}{|l|c|c|c|c|}
\hline & qCON & & qNOX & \\
\hline & Mean & SD & Mean & SD \\
\hline Response & 59.07 & 15.91 & 78.45 & 27.00 \\
\hline No response & 47.88 & 12.99 & 59.02 & 20.23 \\
\hline Pk(SE) & 0.71 & 0.10 & 0.75 & 0.13 \\
\hline p (Krus Wal) & 0.06 & & 0.03 & \\
\hline
\end{tabular}





Fig. 1 Example of the time course of qCON and qNOX of a representative patient.

Table 4 shows that the qCON decreased below 85 at (median) $148.5 \mathrm{~s}$ and below 65 at $183 \mathrm{~s}$ after anaesthesia induction, while the qNOX fall times were significantly longer (p-value $<0.05$ ). During recovery, the qNOX increased above 65 at (median) $57 \mathrm{~s}$ before recovery of consciousness and above 85 at $5 \mathrm{~s}$ after recovery of consciousness while the qCON increased to 85 at 96 seconds after qNOX ( $p$-value $<0.05)$.

Table 4. Fall and rise times for the qCON and qNOX.

\begin{tabular}{|c|c|c|c|}
\hline & $\begin{array}{l}\text { qNOX Time }(\mathrm{s}) \\
\text { median }\left(25^{\text {th }} ; 75^{\text {th }}\right. \\
\text { percentiles })\end{array}$ & $\begin{array}{l}\text { qCON Time }(\mathrm{s}) \\
\text { median }\left(25^{\text {th }} ; 75^{\text {th }}\right. \\
\text { percentiles })\end{array}$ & $\begin{array}{l}\text { qCON - qNOX Time (s) } \\
\text { median }\left(25^{\text {th }} ; 75^{\text {th }}\right. \\
\text { percentiles })\end{array}$ \\
\hline \multicolumn{4}{|c|}{$\begin{array}{l}\text { DECREASIN } \\
\text { G }\end{array}$} \\
\hline$T_{<85}-T_{0}$ & $198.0(114.0 ; 245.0)^{*}$ & $148.5(67.0 ; 190.0) *$ & $-24.0(-64.0 ;-11.0) * *$ \\
\hline$T_{<65}-T_{0}$ & $249.0(189.0 ; 322.0)$ * & $183.0(122.0 ; 241.0)$ * & $-36.5(-113.0 ;-18.0) * *$ \\
\hline \multicolumn{4}{|c|}{ INCREASING } \\
\hline$T_{>65}-T_{R C}$ & $-57.0(-171.0 ; 7.0) *$ & $-1.0(-32.0 ; 60.0)^{*}$ & $22.0(3.0 ; 122.0) * *$ \\
\hline$T_{>85}-T_{R C}$ & $5.0(-44.0 ; 46.0) *$ & $88.0(-151.0 ;-40.0) *$ & $96.0(26.0 ; 184.0) * *$ \\
\hline
\end{tabular}



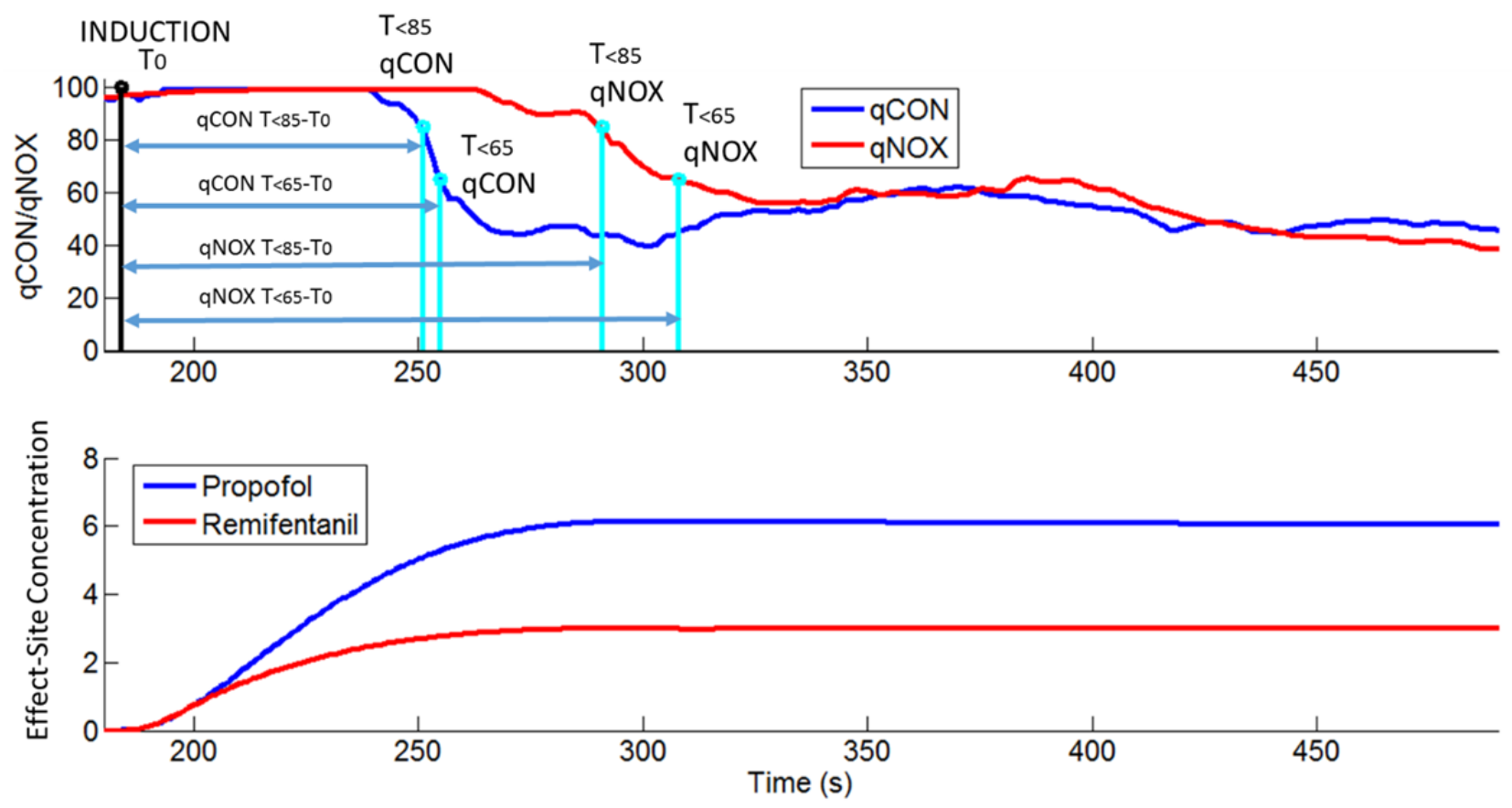

(a)
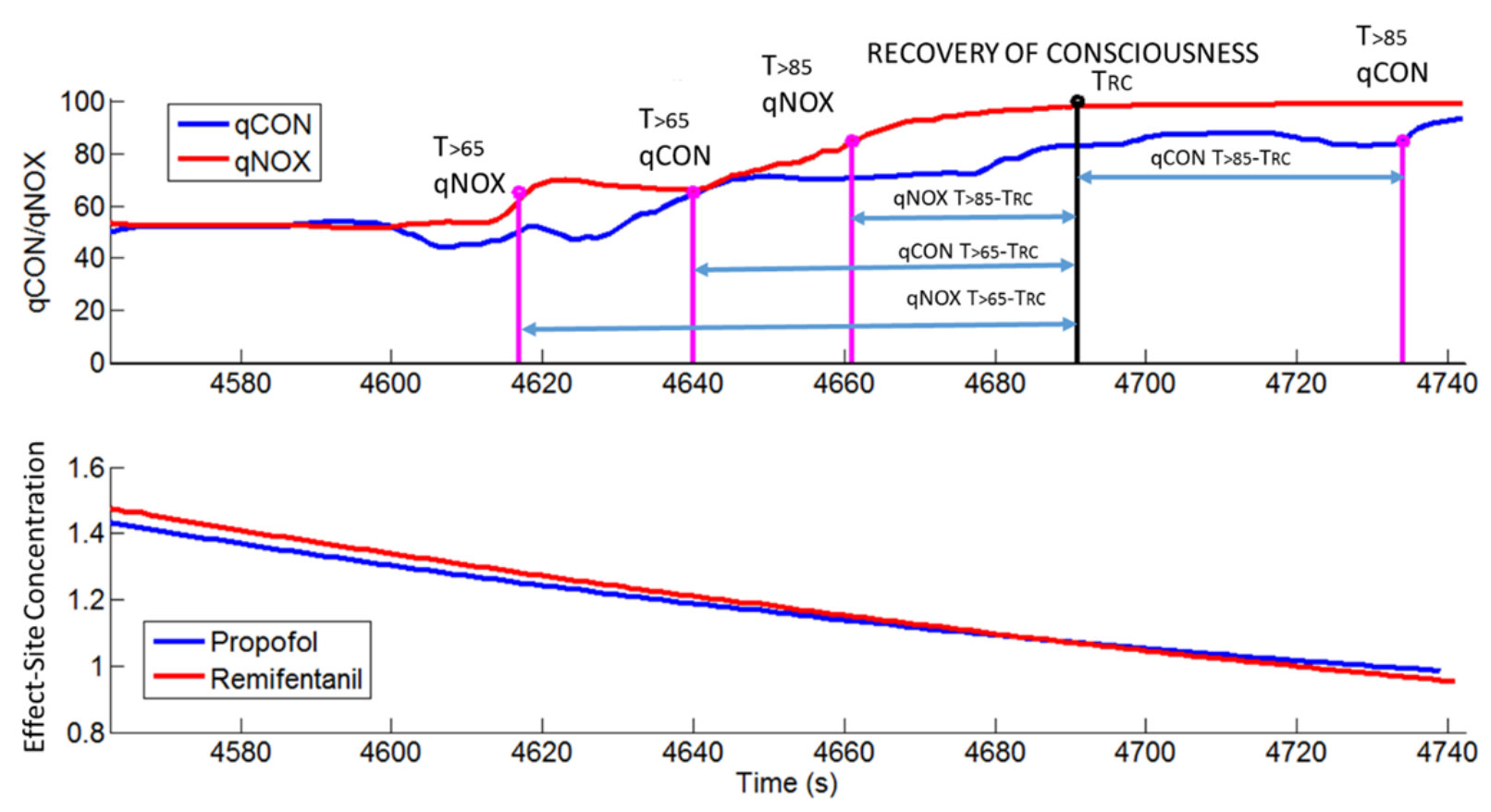

(b)

Fig. 2 Example of qCON and qNOX decreasing and increasing time calculation (a) after drug induction and (b) during recovery of consciousness

Table 5 shows the values of the differences between the time of starting propofol $\left(T_{\text {Prop }}\right)$ or remifentanil $\left(T_{\text {Remi }}\right)$ and the time values when qCON and qNOX decreased under 65 . The fall time calculated with respect to the $T_{\text {Propo }}$ is in general shorter than the fall time calculated with respect to the $T_{\text {Remi }}$, for both qCON and qNOX. However, the qNOX showed a slower fall time ( $p$-value $<0.05$ ) than $\mathrm{qCON}$ for both case of propofol and remifentanil. The averaged time differences between $T_{\text {Remi }}$ and $T_{\text {Propo }}$ resulted in a median of $97(3 ; 125)$ seconds. In order to 
study its influence on the results, the Pearson correlation between the time differences of starting of propofol and remifentanil and the differences between times when qCON and qNOX fallen under $65\left(T_{\text {Remi }}-T_{\text {Propo }}\right.$ versus $\left.q C O N T_{<65}-q N O X T_{<65}\right)$ was calculated and resulted equal to -0.0508 .

Table 5. Values of decreasing time of qCON and qNOX with respect to remifentanil and propofol.

\begin{tabular}{|l|l|l|}
\hline & $\begin{array}{l}\text { qNOX Time (s) } \\
\text { median (25 } \\
\text { percentiles) }\end{array}$ & $\begin{array}{l}\text { qCON Time (s) } \\
\text { median }\left(\mathbf{2 5}^{\text {th }} ; \mathbf{7 5}^{\text {th }}\right. \\
\text { percentiles) }\end{array}$ \\
\hline DECREASING & $257.0(194.0 ; 325.0)^{*}$ & $185.0(133.0 ; 244.0) *$ \\
\hline$T_{<65}-T_{\text {Remi }}$ & $164.5(113.0 ; 238.0) *$ & $92.5(66.0 ; 141.0) *$ \\
\hline$T_{<65}-T_{\text {Propo }}$ & ${ }^{*}$ p-value $<0.005$ Wilcoxon signed-rank test
\end{tabular}

Pearson Correlation $\left(T_{\text {Remi }}-T_{\text {Propo }} v s . q C O N T_{<65}-q N O X T_{<65}\right)=-0.0508$ 


\section{Discussion}

Based on the results of tables 1-3 it was possible to define the ranges for qCON and qNOX indicating loss of consciousness and loss of response to noxious stimulation, respectively. By using these values it was found that the qCON has a faster decrease than the qNOX after drug induction as shown in table 4. At the end of the recording, qNOX started to rise before the qCON (p-value $<0.05$ ). This implies that during recovery the probability of response to noxious stimuli assessed by the qNOX increases before the patient recovered consciousness, as assessed by the qCON.

The results of Table 1 and 2, show that the mean value of the qCON at the moment of no response of verbal command and loss of eyelash reflex was already under 70, while the mean value of qNOX was yet higher than 75 .

Furthermore, observing the results in table 3, it can be deduced that during LMA insertion, the patients classified in the response group were already unconscious (mean value of the qCON below 60) but the mean value of qNOX was above 70. The clinical interpretation of all those results is that loss of consciousness is achieved before analgesia after anaesthesia induction. It also gives guidance to clinicians as how to control anesthetic effect by looking at qCON and qNOX as indicators of hypnosis and analgesia.

The median time difference between $T_{\text {Remi }}$ and $T_{\text {Propo }}$ was $97 \mathrm{~s}$, meaning that remifentanil was started $97 \mathrm{~s}$ before propofol (median). However, no correlation was found between the time differences of starting of propofol and remifentanil and the differences between times when qCON and qNOX had fallen below 65. In this way, it can be assumed that the differences between qCON and qNOX fall times were not influenced by the differences between the time of starting of propofol and remifentanil. Thus, the statistical differences between the fall times of the two indices can be only explained by the different features of qCON and qNOX that are able to assess unconsciousness and unresponsiveness, respectively.

As shown in table 5, the fall times calculated with respect to the start of propofol infusion were shorter than the fall time calculated with respect to the remifentanil, for both qCON and qNOX. This means that the changes in EEG produced by remifentanil occurred later than the changes produced by propofol. Since qNOX showed higher fall times than qCON (p-value $<0.05)$ in both cases, it can be assumed that qNOX is more accurate for detecting the analgesic effects induced in EEG.

The results also show that the qCON has a predictive value of loss of consciousness such as loss of verbal command and eyelash reflex while the qNOX has a predictive value of response to noxious stimulation such as LMA insertion.

The qCON had a lower Pk than the qNOX for prediction of LMA insertion (Table 3) whereas the opposite was the case for lighter stimuli and loss of response to verbal command (Table 1 and 2). Since loss of response to verbal command is an indicator of loss of consciousness, the $\mathrm{Pk}$ was higher for the $\mathrm{qCON}$ than the $\mathrm{qNOX}$, while in case of response to nociceptive stimulation, the qNOX reached higher Pk than the qCON

It is known that when using intravenous anesthetic drugs, the first order rate constant, $\mathrm{k}_{\mathrm{e} 0}$, and its corresponding half-time determine the pseudo-equilibration time between the concentration in plasma and the concentration at the effect site, the biophase concentration. From the 
pharmacokinetics and the value of $\mathrm{k}_{\mathrm{e} 0}$ it can be estimated the time course of drug effect including its onset and offset [30]. Considering the model of the present study, the $\mathrm{k}_{\mathrm{e} 0}$ of propofol was estimated to be $0.46 \mathrm{~min}^{-1}$ corresponding to a time of peak effect concentration of $1.7 \mathrm{~min}$ [2526]. Another study demonstrated that in the case of a single dose of propofol, peak effect concentration is obtained after about 4 min [31] while $80 \%$ of a final target concentration will be achieved at the effect site within about 6 min [32]. Wakeling et al. [33] found that a $\mathrm{k}_{\mathrm{e} 0}$ of $0.63 \mathrm{~min}^{-1}$ for propofol determined a loss of responsiveness in $1.23 \mathrm{~min}$, and with a simulation they found that the desired effect site concentration was reached after $2 \mathrm{~min}$. The present work shows consistent results with all these studies, obtaining a fall of the qCON under 65 between 2 and 4 min after drug induction. Even though, it would be interesting to estimate the value of $\mathrm{k}_{\mathrm{e} 0}$ optimized for qCON as it was done for BIS elsewhere [34].

The onset of remifentanil was studied by its half-time for equilibration between plasma and its effect compartment ( $\mathrm{t} 1 / 2 \mathrm{k}_{\mathrm{e} 0}$ of $\left.1.0-1.5 \mathrm{~min}\right)[35,36]$. This $\mathrm{t} 1 / 2 \mathrm{k}_{\mathrm{e} 0}$ resulted in a time to peak drug effect after a bolus of $1.5 \mathrm{~min}$.

Considering the effect on the EEG, the time to reach a steady-state concentration was demonstrated to be approximately $5 \mathrm{~min}$ to $70 \%$ of the final concentration or $10 \mathrm{~min}$ to $95 \%$ of the steady state [37] These values are consistent with those observed for the fall time of the qNOX. In this way, since the qNOX showed higher fall times than qCON, it can be assumed that qNOX is more accurate for detecting the effects in EEG induced by opioid analgesic drugs. The plasma-effect site equilibration for BIS has been recently calculated to be approximately $5.6 \mathrm{~min}$ [34]. However, there is evidence to suggest that BIS values do not reflect all components of anaesthesia [38]' since opioids do not produce the basic anaesthesia-related EEG pattern. In general, opioids produce a dose-related decrease in frequency and increase in amplitude of the EEG. If further doses of opioids are not given, as with other drug, the opioid effect ceases and then alpha and beta activity will eventually return. The speed of return will depend on the drug itself and the amount given. Complete suppression of the EEG cannot be obtained with opioids and the potential interactive effect with hypnotics is an area worthy of further study. It is well known that indexes of consciousness such as qCON and BIS are designed to optimally correlate with the hypnotic effect on the EEG, while the results of this works suggest that qNOX index can better detect the changes in the EEG induced by the analgesic component. In this way, the use of a nociception index, associated with a hypnotic index, might help to indicate when an unresponsive state is reached with higher precision than when only a consciousness index is used.

Considering the recovery of consciousness, qNOX showed a faster increase than qCON (pvalue $<0.05$ ). It can be deduced that the qNOX is able to detect quickly a change between unresponsive and responsive state compared with the qCON and it might help preventing pain during loss of consciousness. In a previous study [39], the mean time from the end of propofol and remifentanil infusions to 50\% return of responsiveness is shown to be between 6 and 11 min depending on the dose combination of the hypnotic and opioid. Another study demonstrated a rapid termination of remifentanil effect investigating the recovery from respiratory depression [40], in this way also its analgesic effect terminates rapidly. Observing the results of the present work, it is deduced that the end of the analgesic effect is described by the qNOX behavior during recovery of consciousness better than the qCON. 
A limitation of this work is that the start time of infusion of propofol with respect to remifentanil is not the same for all the patients. In median, remifentanil infusion started $97 \mathrm{~s}$ before propofol, however in some case the start time differences was only $5 \mathrm{~s}$ and in a few cases propofol infusion started before remifentanil. In order to estimate and compare better the falling times of the two indexes, the same values of start time of propofol infusion with respect to remifentanil should be taken into account. However, no correlation (Pearson coefficient = 0.0508) was found between the time differences of starting propofol and remifentanil and the differences between times when qCON and qNOX fallen under 65. In this way, the value of starting time of propofol with respect to remifentanil was not used as an exclusion criterion and it was possible to include in the study a high number of patients.

To our knowledge this is the first study where the time of response to a change in the anesthetic state of both consciousness and nociception indexes were calculated and compared. Although the absence of a purposeful motor response has been traditionally used to determine anaesthetic potency [41] ,there is evidence to suggest that loss of consciousness and response to noxious stimuli are not consistent with a scale of increasing 'depth' of anesthesia but rather are two separate phenomena [42].

From all the previous results, it can be deduced that the qNOX is able to quickly detect a change between unresponsive and responsive states compared with the qCON and it might avoid situations of pain during loss and recovery of consciousness. The results of the present work confirm that the use of only a consciousness index is not enough in order to detect the effect of the analgesic induced in the EEG, and thus to monitor the responsiveness of the patients.

\section{Conclusion}

The qCON was able to predict loss of consciousness such as loss of verbal command and eyelash reflex while the qNOX was able to better predict response to noxious stimulation such as LMA insertion.

The indexes qCON and qNOX were able to detect differences between the times of actions of hypnotic and analgesic agents. The qCON showed faster decrease during induction while the qNOX showed a faster increase during recovery. This demonstrated that the probability of response to noxious stimuli increases before the patient recovered consciousness as assessed by the qCON. Hence the qNOX could be interpreted as an arousability index, indicating that the patient is likely to wake up.

\section{Acknowledgement}

The qNOX was based on an idea from the Department of Anesthesia Hospital CLINIC de Barcelona (Spain) funded by grant PS09/01209 of the Fondo de Investigaciones Sanitarias (FIS), Health Department, Government of Spain and has been developed in collaboration with Quantium Medical. 


\section{Conflicts of interest}

Umberto Melia, Erik Weber Jensen, Joan Fontanet, Eva Gabarron and Patricia Pineda are employees of Quantium Medical. Quantium Medical is the commercial developer of both qCON and qNOX indices.

\section{References}

1. Lennmarken C, Sandin R (2004) Neuromonitoring for awareness during surgery. Lancet $363: 1747-1748$.

2. Vakkuri A, Yli-Hankala A, Sandin R, Mustola S, Høymork S, Nyblom S, Talja P, Sampson T, van Gils M, Viertiö-Oja H (2005) Spectral entropy monitoring is associated with reduced propofol use and faster emergence in propofol-nitrous oxide-alfentanil anesthesia. Anesthesiology 103:274-279.

3. Recart A, White PF, Wang A, Gasanova I, Byerly S, Jones SB (2003) Effect of auditory evoked potential index monitoring on anesthetic drug requirements and recovery profile after laparoscopic surgery: a clinical utility study. Anesthesiology 99:813-818.

4. Monk TG, Saini V, Weldon BC, Sigl JC (2005) Anesthetic management and one-year mortality after noncardiac surgery. Anesth Analg 100:4-10.

5. Bruhn J, Myles PS, Sneyd R, Struys MM (2006) Depth of anaesthesia monitoring: what's available, what's validated and what's next? Br J Anaesth 97: 85-94.

6. Mashour GA, Shanks A, Tremper KK, Kheterpal S, Turner CR, Ramachandran SK, Picton P, Schueller C, Morris M, Vandervest JC, Lin N, Avidan MS (2012) Prevention of intraoperative awareness with explicit recall in an unselected surgical population: a randomized comparative effectiveness trial. Anesthesiology Oct 117(4):717-25.

7. Migeon A, Desgranges FP, Chassard D, Blaise BJ, De Queiroz M, Stewart A, Cejka JC, Combet S, Rhondali O (2013) Pupillary reflex dilatation and analgesia nociception index monitoring to assess the effectiveness of regional anesthesia in children anesthetised with sevoflurane. Paediatr Anaesth 23(12):1160-1165. 
8. Jensen EW, Lindholm P, Henneberg SW (1996) Autoregressive modeling with exogenous input of middle-latency auditory-evoked potentials to measure rapid changes in depth of anesthesia. Methods Inf Med 35(3):256-260.

9. Henneberg SW, Rosenborg D, Jensen EW, Ahn P, Burgdorff B Thomsen LL (2005) Peroperative depth of anaesthesia may influence postoperative opioid requirements. Acta Anaesthesiol Scand 49:2293-96.

10. Rehberg B, Ryll C Hadzidiakos D, Dincklage FW, Baars JH (2008) Variability comparison of the composite auditory evoked potential index and the bispectral index during propofol-fentanyl anesthesia. Technology, Computing and Simulation 107(1):117-124.

11. Jensen EW, Litvan H, Revuelta M, Rodriguez BE, Caminal P, Martinez P, Vereecke H, Struys MM (2006) Cerebral state index during propofol anesthesia: a comparison with the bispectral index and the A-line ARX index. Anesthesiology 105:28-36.

12. Boselli E, Daniela-Ionescu M, Bégou G, Bouvet L, Dabouz R, Magnin C, Allaouchiche B (2013) Prospective observational study of the non-invasive assessment of immediate postoperative pain using the analgesia/nociception index (ANI). Br J Anaesth 111(3):453-459.

13. Storm H (2008) Changes in skin conductance as a tool to monitor nociceptive stimulation and pain. Curr Opin Anaesthesiol 21(6):796-804.

14. Schneider G, Jordan D, Schwarz G, Bischoff P, Kalkman CJ, Kuppe H, Rundshagen I, Omerovic A, Kreuzer M, Stockmanns G, Kochs EF (2014) Monitoring depth of anesthesia utilizing a combination of electroencephalographic and standard measures. Anesthesiology 120(4):819-828.

15. Ben-Israel N, Kliger M, Zuckerman G, Katz Y, Edry R (2013) Monitoring the nociception level: a multi-parameter approach. Journal of clinical monitoring and computing 27(6):659-668.

16. Barvais L, Engelman E, Eba, JM, Coussaert E, Cantraine F, Kenny GN (2003) Effect site concentrations of remifentanil and pupil response to noxious stimulation. British journal of anaesthesia 91(3):347-352. 
17. Rollins MD, Feiner JR, Lee JM, Shah S, Larson M (2014) Pupillary effects of high-dose opioid quantified with infrared pupillometry. Anesthesiology 121(5):1037-1044.

18. Gruenewald M, Ilies C, Herz J, Schoenherr T, Fudickar A, Höcker J, Bein B (2013). Influence of nociceptive stimulation on analgesia nociception index (ANI) during propofolremifentanil anaesthesia. Br J Anaesth 110:1024-1030.

19. Luginbuhl M, Schumacher PM, Vuilleumier P, Vereecke H, Heyse B, Bouillon TW, Struys M (2010) Noxious Stimulation Response Index: A Novel Anesthetic State Index Based on Hypnotic-Opioid Interaction. Anesthesiology 112(4):872-880.

20. Bouillon TW, Bruhn J, Radulescu L, Andresen C, Shafer TJ, Cohane C, Shafer SL (2004) Pharmacodynamic interaction between propofol and remifentanil regarding hypnosis, tolerance of laryngoscopy, bispectral index, and electroencephalographic approximate entropy. Anesthesiology 100:1353-1372.

21. Vereecke HEM, Hannivoort L N, Proost J H, Eleveld D J, Struys MMRF, Luginbühl M (2014) Predictive Performance of the Noxious Stimulation Response Index as a Measure of Anesthetic Potency during Sevoflurane, Propofol and Remifentanil Anesthesia. International Society for Anaesthetic Pharmacology (ISAP) Annual Meeting 2014. http://f1000research.com/posters/1097048.

22. von Dincklage F, Correll C, Schneider MH, Rehberg B, Baars JH (2012) Utility of Nociceptive Flexion Reflex Threshold, Bispectral Index, Composite Variability Index and Noxious Stimulation Response Index as measures for nociception during general anaesthesia. Anaesthesia 67(8):899-905.

23. Gambús PL, Jensen EW, Jospin M, Borrat X, Martínez Pallí G, Fernández-Candil J, Valencia JF, Barba X, Caminal P, Trocóniz IF (2011) Modeling the effect of propofol and remifentanil combinations for sedation-analgesia in endoscopic procedures using an Adaptive Neuro Fuzzy Inference System (ANFIS). Anesth Analg 112(2):331-339.

24. Schnider TW, Minto CF, Shafer SL, Gambus PL, Andresen C, Goodale DB, Youngs EJ (1999) The influence of age on propofol pharmacodynamics. Anesthesiology 90:1502-1516. 
25. Schnider TW, Minto CF, Gambus PL, Andresen C, Goodale DB, Shafer SL, Youngs EJ (1998) The influence of method of administration and covariates on the pharmacokinetics of propofol in adult volunteers. Anesthesiology 88:1170-1182.

26. Minto CF, Schnider TW, Egan TD, Youngs E, Lemmens HJ, Gambus PL, Billard V, Hoke JF, Moore KH, Hermann DJ, Muir KT, Mandema JW, Shafer SL (1997) Influence of age and gender on the pharmacokinetics and pharmacodynamics of remifentanil: I. Model development. Anesthesiology 86:10-23.

27. Minto CF, Schnider TW, Shafer SL (1997) Pharmacokinetics and pharmacodynamics of remifentanil: II. Model application. Anesthesiology 86:24-33.

28. Altman DG (1991) Practical statistics for medical research. Chapman \& Hall, London.

29. Smith WD, Dutton RC, Smith NT (1996) Measuring the performance of anesthetic depth indicators. Anesthesiology 84:38-51.

30. Irwin MG, Hui TWC, Milne SE, Kenny GNC (2002) Propofol effective concentration 50 and its relationship to bispectral index. Anaesthesia 57(3):242-248.

31. Gepts E (1998) Pharmacokinetic concepts for TCI anaesthesia. Anaesthesia 53: 4-12.

32. Stuart PC, Stott SM, Millar A, Kenny GN, Russell D (2000) Propofol with and without nitrous oxide. British Journal of Anaesthesia 85:666.

33. Wakeling HG, Zimmerman JB, Howell S, Glass PSA (1999) Targeting effect compartment or central compartment concentration of propofol. Anesthesiology 90:92-97.

34. Borrat X, Trocóniz IF, Valencia JF, Rivadulla S, Sendino O, Llach J, Castells A (2013). Modeling the Influence of the A118G Polymorphism in the OPRM1 Gene and of Noxious Stimulation on the Synergistic Relation between Propofol and Remifentanil Sedation and Analgesia in Endoscopic Procedures. The Journal of the American Society of Anesthesiologists 118(6):1395-1407. 
35. Glass PS, Hardman D, Kamiyama Y, Quill TJ, Marton G, Donn KH, Hermann D (1993) Preliminary pharmacokinetics and pharmacodynamics of an ultra-short-acting opioid: remifentanil (GI87084B). Anesth Analg 77:1031-1040.

36. Egan TD, Lemmens HJ, Fiset P, Hermann DJ, Muir KT, Stanski DR, Shafer SL (1993) The pharmacokinetics of the new short-acting opioid remifentanil (GI87084B) in healthy adult male volunteers. Anesthesiology 79:881-892.

37. Glass PS, Gan TJ, Howell S (1999) A review of the pharmacokinetics and pharmacodynamics of remifentanil. Anesthesia \& Analgesia 89(4S):7.

38. Kissin I. (2000) Depth of anaesthesia and bispectral index monitoring. Anesthesia and Analgesia 90: 1114-1117.

39. Tams C, Johnson K (2014) Prediction Variability of Combined Pharmacokinetic Pharmacodynamic Models: A Simulation Study of Propofol in Combination with Remifentanil and Fentanyl. J Anesth Clin Res 5:393.

40. Kapila A, Glass P, Jacobs J, Muir K, Hermann D, Shiraishi M, Smith R (1995) Measured context-sensitive half times of remifentanil and alfentanil. Anesthesiology 83:968975.

41. Zbinden AM, Maggiorini M, Petersen-Felix S, Lauber R, Thomson DA, Minder CE (1998) Anesthetic depth defined using multiple noxious stimuli during isoflurane/oxygen anesthesia. I. Motor reactions. Anesthesiology 1994; 80: 253-60.

42. Katoh T, Ikeda K. The effects of fentanyl on sevoflurane requirements for loss of consciousness and skin incision. The Journal of the American Society of Anesthesiologists 88(1):18-24. 